\title{
Trends in hydro-climatic variables and dissolved oxygen of the river Periyar, South India with potential impacts of global warming
}

\author{
E. Lakshmi ${ }^{1}$ \& G. Madhu ${ }^{2}$ \\ ${ }^{1}$ School of Environmental Sciences, Mahatma Gandhi University, India \\ ${ }^{2}$ School of Engineering, Cochin University of Science and Technology, India
}

\begin{abstract}
The study has aimed to evaluate the changes in air temperature, surface water temperature, rainfall, discharge (flow) and dissolved oxygen during the last 30 years in Periyar River, the longest river in Kerala, from a climate change perspective. Trend analysis is carried out on the 30 year annual average data of hydro-climatic variables (air temperature, surface water temperature, discharge, rainfall, and dissolved oxygen) of the river to forecast scenarios for 2020, 2040, 2060, 2080, 2100. Statistical analysis, correlation and simple linear regression are performed on the secondary data to derive equations relating to hydroclimatic variables. Emission scenarios, hypothesized for South Asian countries in the Global Circulation model output given in the Intergovernmental Panel on Climate Change (IPCC) report 2007, are then applied in the equations so derived, to predict surface water temperature and discharge of the river. The projections for dissolved oxygen, surface water temperature, and discharge are carried out using a time series model through SPSS 6.1 software. From the trend analysis we could infer that for each scenario considered there is an increasing trend for all variables except for dissolved oxygen. Time series model indicates that there is reduction in dissolved oxygen and an increase in discharge and surface water temperature of the river by the year 2100. It is apparent from the results that the dissolved oxygen is found to decrease with an increase in surface water temperature. Such inferences will be helpful in modifying the current management plans in practice and for deciding future management plans which are to be implemented, in mitigating the effects on the already polluted river.
\end{abstract}


Keywords: climate change, hypothetical scenario, hydro-climatic variables, river water quality, simple linear regression, time series model, emission scenarios.

\section{Introduction}

The phenomenon called "climate change" is one of the most researched topics in recent times. From a global perspective, climate change is usually perceived as an increase in average air temperature. Consequently the increase in the air temperature will have a definitive impact on the surface water temperature .Subsequently this change would cause changes in runoff, river flow, ground water storage, water temperature and discharge of the river [1].

The scientific consensus is that future increases in atmospheric greenhouse gas concentrations will result in elevated global-mean temperatures with subsequent effects on regional precipitation, evapo-transpiration, soil moisture and altered flow regimes in streams and rivers [2]. Most of the chemical reactions and bacteriological processes are dependent on temperature and they run faster at high temperatures, increasing the growth rates. The direct impact of an increased temperature will hence be on dissolved oxygen [3]. Climate change results in deterioration of water quality in terms of reduction in dissolved oxygen concentration, high levels of which are needed to sustain aquatic life. These adverse effects will worsen with changes in river flow and increased pollutants. Changes in air temperature and rainfall can affect river flow and river water temperature, the primary variables that influence water quality [1]. Therefore, in this article an attempt is made to assess the impacts of climate change on dissolved oxygen in the Periyar River under different emission scenarios.

Periyar River is one of the longest flowing rivers in Kerala, South India; with a catchment area of $5398 \mathrm{~km}^{2}$ [4]. The river plays an important role in the cultural, political and socio-economic aspects of the people in central Kerala. Major tributaries of the river are Muthirapuzha River, Mullayar River, Cheruthoni River, Perinjamkutti River, and Edamala River. Minor tributaries are Muthayar, Perunthuraiar, Chinnar, Cheruthony, Kattappanayar [4]. The river is divided into two branches at the Eloor Island to join back at the Eloor ferry, further flowing down stream to join the Arabian Sea. Eloor-Edayar belt is sprawling with small and large-scale industries, which discharge semi-treated and untreated effluents into the river. Samples are collected from Periyar River near the Eloor-Edayar belt. Green peace, India describes the lower Periyar as "a cesspool of toxins, which has alarming levels of deadly poisons like DDT, endosulfan, hexa and trivalent chromium, lead, cyanide, BHC” etc. The Central Pollution Control Board started national water quality monitoring in 1978 under Global Environment Monitoring System (GEMS) water program [5].

Here, in this article historical data retrieved from the water quality program of hydro-climatic variables are analyzed to predict future trends in the river. Water temperature data is then correlated and analyzed with the dissolved oxygen of the river to propose predictions for surface water temperature and discharge of the river for the future. 


\section{Methodology}

Periyar River is one of the most polluted rivers in India. Dissolved oxygen in the river is found to be very low and fluctuating, due to discharge of effluents from semi-treated and untreated waste water from the nearby industries into the river. Around 500 small and large scale industries are there in the Eloor-Edayar belt which discharge pollutants daily into the river [4]. Inhabitants in the Eloor Island depend on the river for drinking, agriculture, and other domestic purposes. This disastrous condition of the river has made the life of the people miserable. So, trend analysis and correlation and regression analysis of hydro-climatic variables and its forecasting will help in planning management strategies in reducing pollution of the river.

Secondary data of variables from the Periyar River during 1980-2011 was obtained from the Kerala State Pollution Control Board, Indian Meteorological Department, Neeleswaram station of Central Water Commission, Kochi and Kerala State Hydrology Department, Thiruvananthapuram for surface water temperature, air temperature, discharge and rainfall respectively.

Studies show that dissolved oxygen in the water gets reduced with an increase in water temperature. In order to understand the relation between dissolved oxygen and hydro climatic variables in the river especially surface water temperature, primarily a trend analysis was performed for all the variables [6].Thirty years annual average data of surface water temperature, air temperature, discharge, rainfall and dissolved oxygen are used for analyzing the trend [7-9]. 30 years is taken as the time period and average annual data as the time unit. Difference of data between the first year and second year are recorded. Continuing in this manner, the recording for the difference in data between each time unit is carried out until the 30 year time period is over. Add all the data to get total for all the time units. Divide the sum total by the number of time units over the time period. The resulting data is used for predicting the surface water temperature, air temperature, rainfall, discharge and dissolved oxygen for 2020, 2040, 2060, 2080, and 2100. This data is then subjected to correlation and simple linear regression statistical analysis using SPSS 6.1 software. The equations obtained from the linear regression analysis are used to predict values of surface water temperature and discharge of the river from the air temperature (emission scenario) hypothesized in GC model output in the IPCC report, 2007 [10].

The Special Report on Emission Scenarios (SRES), described in the IPCC report 2007 [11, 12] with SRES 2000 as the base, are grouped into four scenario families (A1, A2, B1 and B2) that explore alternative development pathways, covering a wide range of demographic, economic and technological driving forces and resulting GHG emissions.

The A1 storyline assumes a world of very rapid economic growth, a global population that peaks in mid-century and rapid introduction of new and more efficient technologies. A1 is divided into 3 groups that describe alternative directions of technological change: fossil intensive (A1F1), non fossil energy resources (A1T) and a balance across all sources (A1B). B1 describes a convergent world, with the same global population as $\mathrm{A} 1$, but with more rapid 
changes in economic structures towards a service and information economy. B2 describes a world with intermediate population and economic growth, emphasizing local solutions to economic, social and environmental sustainability. A2 describes a very heterogeneous world with high population growth, slow economic development and slow technological change.

For each emission scenario, corresponding increase in air temperature is given in the IPCC report 2007. So, corresponding air temperature is introduced into the equations derived from simple linear regression for each scenario. From the equations derived, we can predict values for water temperature and discharge of the river for the year 2100. Time series model of SPSS 6.1 software is used for projecting the surface water temperature, discharge and dissolved oxygen of the river for the next 100 years [13].

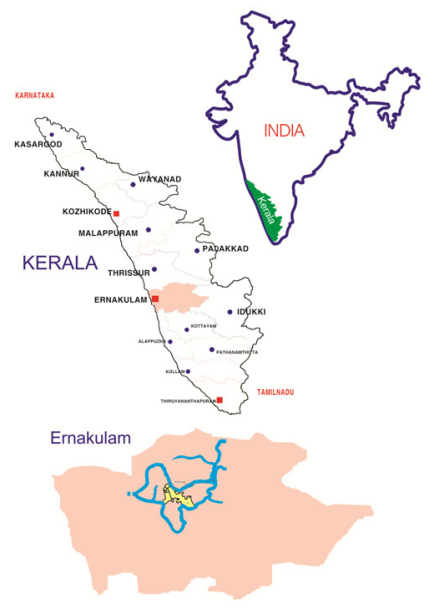

Figure 1: $\quad$ Showing the sampling site.

\section{Results}

Correlation analysis of the data collected suggests that dissolved oxygen is inversely related to water temperature i.e., higher the water temperature, lower the dissolved oxygen. But, surface water temperature is in turn affected by air temperature and rainfall of the region, and discharge of the river. Here, in this article in order to project the variations of dissolved oxygen of the river by 2100 , thirty years secondary data of air temperature, surface water temperature, rainfall and discharge are analyzed using statistical software SPSS 6.1.

Hydro-climatic variables are analyzed for the trend for 30 years. Analysis shows that water temperature $\left(0.012^{\circ} \mathrm{C} / \mathrm{yr}\right)$, air temperature $\left(0.018^{\circ} \mathrm{C} / \mathrm{yr}\right)$, rainfall $(2.008 \mathrm{~mm} / \mathrm{yr})$ and discharge $\left(1.169 \mathrm{~m}^{3} / \mathrm{s} / \mathrm{yr}\right)$ shows an increasing trend while, dissolved oxygen $(2.02 \mathrm{mg} / \mathrm{l} / \mathrm{yr})$ shows a decreasing trend.

Here for the current study, year 2000 is taken as the base value for the evaluation of different scenarios. The results obtained are given in table 3. 
Table 1: $\quad 30$ year annual mean variation of Air temperature $\left({ }^{\circ} \mathrm{C}\right)$, Water temperature $\left({ }^{\circ} \mathrm{C}\right)$, Rainfall $(\mathrm{mm})$, Discharge $\left(\mathrm{m}^{3} / \mathrm{s}\right)$ and dissolved oxygen (mg/l) from 1980 to 2011.

\begin{tabular}{|c|c|c|c|c|c|}
\hline Year & Air Temp & Water Temp & Rainfall & Discharge & $\begin{array}{l}\text { Dissolved } \\
\text { Oxygen }\end{array}$ \\
\hline 1980 & 28.02 & 29.3 & - & 260.51 & 3.58 \\
\hline 1981 & 27.81 & 31.1 & 287.5 & 305.71 & 7.05 \\
\hline 1982 & 27.9 & 30.4 & 209.16 & 121.83 & 5.1 \\
\hline 1983 & 27.91 & 29.6 & 218.3 & 181.0 & 6.67 \\
\hline 1984 & 27.48 & 28.5 & 234.11 & 198.4 & 7.04 \\
\hline 1985 & 27.67 & 30.3 & 242.3 & 207.4 & 6.63 \\
\hline 1986 & 26.46 & 31.4 & 200.9 & 177.12 & 7.0 \\
\hline 1987 & 28.41 & 28.8 & 212.05 & 153.5 & 6.66 \\
\hline 1988 & 27.97 & 29.0 & - & 175.5 & 6.65 \\
\hline 1989 & 27.54 & - & 222.11 & 240.42 & 6.5 \\
\hline 1990 & 27.66 & 28.8 & 204.9 & 195.08 & 7.11 \\
\hline 1991 & 27.86 & 28.6 & - & 314.2 & 6.55 \\
\hline 1992 & 27.43 & 27.4 & - & 256.9 & 6.59 \\
\hline 1994 & 27.54 & 27.4 & 247.5 & 281.08 & 7.0 \\
\hline 1995 & 27.61 & 26.5 & 277.49 & 211.98 & 7.17 \\
\hline 1996 & 27.72 & 28.2 & 202.16 & 190.61 & 7.26 \\
\hline 1997 & 28.02 & 28.7 & 217.11 & 207.95 & 6.8 \\
\hline 1998 & 28.13 & 28.8 & 216.66 & 276.05 & 6.7 \\
\hline 1999 & 27.42 & 24.9 & 215.64 & 181.8 & 6.84 \\
\hline 2000 & 27.44 & 26.1 & 174.93 & 197.51 & 6.84 \\
\hline 2001 & 27.49 & 26.5 & 259.69 & 217.27 & 6.62 \\
\hline 2002 & 27.73 & 27.8 & 262.65 & 167.69 & 5.08 \\
\hline 2003 & 27.91 & 28.3 & 182.15 & 146.84 & 5.41 \\
\hline 2004 & 27.604 & 28.08 & 235.74 & 209.14 & 5.98 \\
\hline 2005 & 28.69 & 27.9 & 266.1 & 294.02 & 5.7 \\
\hline 2006 & 27.65 & 28.0 & 304.37 & 221.71 & 6.19 \\
\hline 2007 & 27.7 & 27.75 & 308.73 & 317.04 & 5.54 \\
\hline 2008 & 27.68 & 28.83 & 219.01 & 176.83 & 5.14 \\
\hline 2009 & 27.96 & 28.0 & 234.65 & 210.75 & 6.04 \\
\hline 2010 & 27.908 & 31.0 & - & 237.25 & 5.32 \\
\hline 2011 & 27.8 & 29.0 & - & - & 5.6 \\
\hline
\end{tabular}

Table 2: $\quad$ Showing proposed hypothetical scenarios.

\begin{tabular}{|c|c|c|c|c|}
\hline Scenario & $\begin{array}{c}\text { Water } \\
\text { temperature }\end{array}$ & Air temperature & Rainfall & Discharge \\
\hline 1 & +2.4 & +0.36 & +40.16 & +23.38 \\
\hline 2 & +0.48 & +0.72 & +80.32 & +46.4 \\
\hline 3 & +0.72 & +1.08 & +120.48 & +69.6 \\
\hline 4 & +0.96 & +1.44 & +160.64 & +92.8 \\
\hline 5 & +1.2 & +1.8 & +200.8 & +116.9 \\
\hline
\end{tabular}

Table 3: $\quad$ Showing results of proposed scenarios.

\begin{tabular}{|l|c|c|c|c|}
\hline Scenario & $\begin{array}{c}\text { Air } \\
\text { temperature }\end{array}$ & $\begin{array}{c}\text { Water } \\
\text { temperature }\end{array}$ & Rainfall & Discharge \\
\hline 2000 & 27.44 & 26.1 & 174.93 & 197.51 \\
\hline Scenario 1 & 27.68 & 26.46 & 215.09 & 220.89 \\
\hline Scenario 2 & 27.92 & 26.82 & 255.25 & 243.91 \\
\hline Scenario 3 & 28.16 & 27.18 & 295.41 & 267.11 \\
\hline Scenario 4 & 28.4 & 27.54 & 335.57 & 290.31 \\
\hline Scenario 5 & 28.64 & 27.9 & 375.73 & 314.41 \\
\hline
\end{tabular}


The relationship between hydro climatic variables of the river was studied by computation of correlation coefficients between them. The climatic and hydrological variables considered are precipitation, discharge, air temperature and water temperature. The correlation results show that there is a significant positive correlation between water temperature and air temperature. From this, it is clear that there will be an increase in river water temperature, with increase in air temperature. Correlation of discharge and rainfall shows significance at $90 \%$ confidence level. Correlation analysis done with dissolved oxygen and water temperature gives a negative correlation between them. So it is apparent that, warmer the water lesser the oxygen dissolved in the river water.

Furthermore, to establish relation between variables, simple linear regression analysis was done between air temperature and water temperature, discharge and rainfall, rainfall and air temperature, dissolved oxygen and temperature and equations are derived. The regression equations are as follows:

$$
\begin{gathered}
\text { Water Temperature }=22.858+0.202 \times \text { Air temperature } \\
\text { Discharge }=5.167+0.880 \times \text { Rainfall } \\
\text { Rainfall }=-60.511+10.62 \times \text { Air temperature } \\
\text { Dissolved Oxygen }=9.197-0.103 \times \text { water temperature }
\end{gathered}
$$

International Panel for Climate Change (2007) has given different emission scenarios for South-Asian region. Based on their observation, they had suggested a respective increase in air temperature for different scenarios which is evaluated for $99 \mathrm{yr}$ time period. These air temperature values for each emission scenario are used for prediction of surface water temperature of the river. Here, 2000 mean annual air temperature $\left(27.42^{\circ} \mathrm{C}\right)$ is taken as the base temperature for calculating temperature change for each scenario [11]. Similarly, equation relating rainfall and discharge (equation (2)) was used to predict discharge of the river from the rainfall scenario. Rainfall data obtained from equation (3) for different scenarios is used in predicting discharge of river by equating in equation (2).

Table 4: Change in air temperature, water temperature, rainfall and discharge for different scenarios (2100yr).

\begin{tabular}{|c|c|c|c|c|}
\hline Scenario & Air temp & Water temp & Rainfall & Discharge \\
\hline B1 & 29.24 & 27.9 & 250.01 & 225.17 \\
\hline A1T & 29.84 & 28.5 & 256.38 & 230.78 \\
\hline B2 & 29.84 & 28.5 & 256.38 & 230.78 \\
\hline A1B & 30.24 & 28.9 & 260.63 & 234.52 \\
\hline A2 & 30.84 & 29.5 & 267.00 & 240.12 \\
\hline A1F1 & 31.44 & 30.1 & 273.38 & 245.74 \\
\hline
\end{tabular}

Here, we could observe that the water temperature and discharge are slightly higher than the one predicted through the trend analysis. A1F1 scenario, a world with rapid population growth and more fossil intensive economic growth scenario projects the highest increase in temperature both for air and water. Here it can be observed that for the scenario (A1F1) where population growth increases, with slow economic and technological changes, the air temperature increases with a corresponding increase in water temperature. Similarly, rainfall 
and discharge of the river is also observed to be on a steady rise for different hypothetical scenarios considered. Results obtained here ascertain the IPCC report of increased temperature and increased precipitation over South-Asia over the next 100 years $[11,12]$. Air temperature predicted through trend analysis for the river basin by 2100 is $28.64^{\circ} \mathrm{C}$, an increase of $1.2^{\circ} \mathrm{C}$, while emission scenarios proposed in the IPCC report suggest an increase of $1.6-3.6^{\circ} \mathrm{C}$ that is, air temperature would be between 29 and $31^{\circ} \mathrm{C}[11,12]$. For water, the increase in temperature is by $1.8{ }^{\circ} \mathrm{C}$ (trend analysis) and the GC model scenarios predict an increase of $1.8-4^{\circ} \mathrm{C}$. Graphical projection of thirty years observed data of surface water temperature, discharge and dissolved oxygen are done with the time series model of SPSS statistical software.

From the time series model graphs, we could forecast the water temperature to be $29^{\circ} \mathrm{C}$ and discharge to be $250 \mathrm{~m}^{3} / \mathrm{s}$ for the year 2100 (figure 2). From figure 3 , we could infer that the dissolved oxygen would be around $5.6 \mathrm{mg}$ of oxygen/l by 2100 .

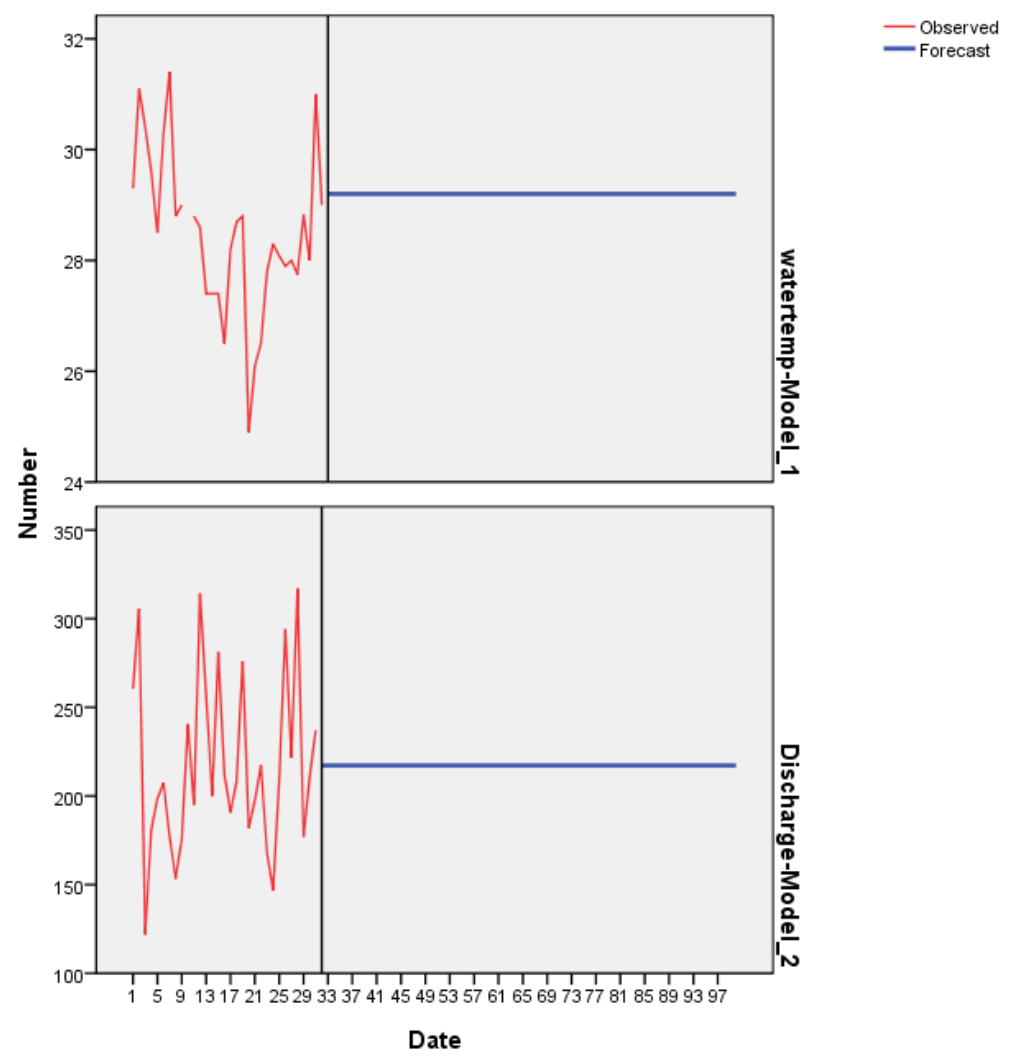

Figure 2: $\quad$ Showing time series model for water temperature and discharge. 


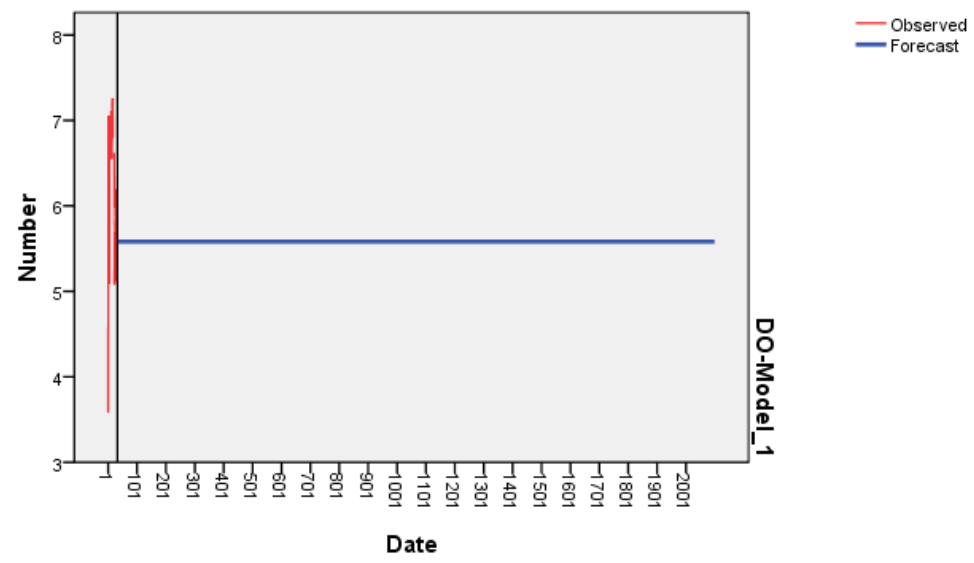

Figure 3: $\quad$ Showing time series model for dissolved oxygen.

From the analysis of different scenarios, we could infer an increase in surface water temperature of 1.8 to $4^{\circ} \mathrm{C}$ by the next 100 year. There is a simultaneous decrease in dissolved oxygen (9.2\%) i.e., dissolved oxygen will be $5.6 \mathrm{mg} / \mathrm{l}$ by 2100 if the water temperature is at $29^{\circ} \mathrm{C}$ and industrial effluent discharge to the river remains at the present status. An increasing temperature has the most impact on de-oxygenation rate, resulting in decreased dissolved oxygen saturation concentration thereby reducing the dissolved oxygen in the river [13]. Thus, lowering of dissolved oxygen in the Periyar River will further worsen the already polluted river. Currently the river receives around 25,314 $\mathrm{m}^{3} /$ day of effluent discharge [14]. As the water temperature increases, the rate of chemical reactions becomes higher, which in turn affects the biological activity, further lowering the dissolved oxygen in the river (water quality assessment: physical temperature). Time series graphs (figures 2 and 3) show the water temperature to be at $29^{\circ} \mathrm{C}$, discharge of the river to be $250 \mathrm{~m}^{3} / \mathrm{s}$ and DO value to be $5.6 \mathrm{mg} / \mathrm{l}$ by 2100yr.

\section{Conclusion}

From the correlation analysis, we could find that all the hydro-climatic variables analyzed were positively correlated. In this article we have analyzed the increasing and decreasing trend of 30 year data of hydro climatic variables of the Periyar River. We observed an increasing trend for all the variables considered; air temperature, water temperature, discharge and precipitation. Based on the results from trend analysis, scenarios were proposed to predict air temperature, water temperature, discharge and rainfall by 2100. Linear regression equation obtained from the regression analysis was used to predict water temperature, and discharge of the river from the air temperature given in the emission scenarios of Global Circulation model output. Results from the scenarios of GC model output were compared with the scenarios of trend analysis. We could observe, slight 
variation in discharge, rainfall, water temperature and air temperature. Time series model developed predicts the surface water temperature to be around $29^{\circ} \mathrm{C}$ and discharge of the river to be $250 \mathrm{~m}^{3} / \mathrm{s}$ by the year 2100 .

30 year data of dissolved oxygen from the Periyar effluent discharge near Eloor showed a negative correlation with water temperature. Trend analysis done to dissolved oxygen, showed a decreasing trend, this is a consequent of effluent discharge to the Periyar River. Time series model developed for dissolved oxygen, water temperature and discharge, predicted the dissolved oxygen in the river to be $5.6 \mathrm{mg} / \mathrm{l}$ by 2100 . In the IPCC report, it is predicted that the air temperature and precipitation of the South Asian region is bound to increase by 2100. This is in corroboration with our results from both, trend analysis and simple linear regression. But, Mathew Huber [15] in nature journal has pointed out that even though climate models indicate an increase in water temperature for tropics, investigations of ancient climates based on palaeodata have indicated cool temperatures or water temperature within the range of $28-32^{\circ} \mathrm{C}$ during the supposed green house episodes. Zachos [16], analyzed sediments deposited on the sea floor during a period known as Paleocene-Eocene thermal maximum, found that a massive release of heat trapping green house gases is thought to have triggered the process of global warming. However, from our study, we could find that the air temperature of the Periyar River is increasing thereby, increasing the surface water temperature of the river. The precipitation and discharge of the river is found to increase with increasing temperature with reduction in dissolved oxygen. Thus, from our analysis we could reaffirm that climate change is a fact. So, strong measures should be made to curb the discharge of polluted effluents into the already polluted Periyar River. New management practices and paradigms that can accommodate changing conditions are needed. Efforts must be made to implement long term adaptation policies as an initial strategy and also to design new treatment systems to include climate change impacts.

\section{References}

[1] Rehana, S., Mujumder, P. P., River Water quality response under hypothetical climate change scenarios in Tunga-Bhadra River, India, Hydrological processes, Wiley online library, 2011.

[2] Arnell, N. W., Wilby et al., Climate change and global water resources, Global Environmental change, 9, pp. 31-49,2004, 1994.

[3] Cox, B. A., Whitehead, P. G., Impacts of climate change scenarios on dissolved oxygen in the river Thames, UK, Hydrology Research, 4(2-3), pp. 138-152, 2009.

[4] Stringer, R., Labunska, I., Brigden, K., Pollution from Hindustan Insecticide Limited and other factories in Kerala, India: A follow-up study, Green Peace Research Laboratories, University of Exeter, UK, 2003.

[5] Central Pollution Control Board, National Water Quality Monitoring, Global Environment Monitoring System (GEMS) water program, 1978. 
[6] Baggaley, N. J., Langan, S. J., Fulter, M. N., Dunn, S. M., Long term trends in hydro-climatology of a major Scottish mountain river, Science Total Environment, 407 (16), pp. 4633-41, 2009.

[7] Edinger, G. J., Duttweiler, D. W., Geyer, J. C., The response of water temperatures to meteorological condition, Water Resources Research, 4 (5), pp. 1137-1143, 1968.

[8] Langan, S. J., Johnston, L., Donaghy, M. J., Youngson, A. F., Hay, D. W., Soulsby, C., Variation in river water temperatures in an upland stream over a 30 year period, Science of the Total Environment, 265 pp. 195-207, 2001.

[9] Mohseni, O., Stefan, H. G., Stream temperature/ air temperature relationship: a physical interpretation, Journal of Hydrology, 218 pp. 128141, 1999.

[10] IPCC (2001) Climate change: Vulnerability, impacts and adaptation, Contribution of Working Group ii to the third assessment report of the Intergovernmental Panel on climate change. In: Mc McCarthy, J., Canziani, O. F., Leary, N. A., Dokken, D. J., White, K. S., (eds). Cambridge University Press. Cambridge. UK. 1 032, 2001.

[11] Climate change, Synthesis Report, An assessment of the intergovernmental panel on climate change, IPCC Planery xxvii (Valencia, Spain, 12-17 November, 2007.

[12] Climate change, Working Group 1, The Physical Science Basis, 2007.

[13] Shumway, R. H., Stoffer, D. S., Time series analysis and its applications, Springerverlag, New York, 2000.

[14] Kerala State Pollution Control Board. Report on discharge of effluents from the industries at Eloor- Edayar belt. Kochi, Kerala, India 2012.

[15] Huber, M., Climate change: Snakes tell a torrid tale .Nature Journal. 457, 669-671, 2009.

[16] Zachos, J., New evidence of global warming in Earth's past supports current models for how climate responds to greenhouse gases, Science express, 2003. 